\title{
IMPACT OF ASSIGNMENT, INVENTORY POLICIES AND DEMAND PATTERNS ON SUPPLY CHAIN PERFORMANCE
}

\author{
Al-Hawari, T.; Ahmed, A.; Khrais, S. \& Mumani, A. \\ Industrial Engineering Department, Jordan University of Science and Technology, Irbid, Jordan \\ E-Mail: tarek321@just.edu.jo, aaahmed09@eng.just.edu.jo, \\ khrais@just.edu.jo,momani_ie2@yahoo.com
}

\begin{abstract}
A simulation model is built to analyse the performance of a four-level/three-product supply chain composed of a retailer, distributor, manufacturer and supplier. The effects of assignment policies; preferred, cyclical and random, were analysed in combination with various factors such as inventory policies; continuous review $(r, Q)$ and periodic review $(T, S)$, and different demand patterns. On-hand inventory and percentage of satisfied customers at various levels of the $\mathrm{SC}$ are used as key performance indicators. In $(T, S)$ systems, it is found that imposing an upper limit on $S$ in some SC levels due to the assumption that an order is shipped as a whole in one trip would greatly influence results. Consequently, an increase in $T$ not associated with a sufficient increase in $S$ would decrease inventory levels that would lead to shortages between orders. In $(r, Q)$ systems, the results show clearly how the effect of increasing $Q$ in one level is transformed to upstream and downstream levels. Upstream levels are all negatively affected, while downstream levels maintain the same levels of inventory without any noticeable trends. ANOVA results show that at low demand rates inventory policies are the most significant, then demand patterns while the assignment policies are mostly insignificant. At high demand rates the assignment policy factor becomes significant as well as the other two factors. Sensitivity analysis performed shows the robustness of the results under varying conditions.

(Received in August 2012, accepted in March 2013. This paper was with the authors 3 months for 3 revisions.)
\end{abstract}

Key Words: Supply Chain Management, Assignment Policies, Inventory Policies, Simulation

\section{INTRODUCTION}

Supply chain (SC) managers are confronted with selecting the most appropriate inventory control policy that would lead to balancing inventory and decreasing cost while maintaining good customer satisfaction and reducing the risk of shortages [1, 2]. Much research has been conducted to study the effects of inventory policies on SC performance. In [3] a study was performed on a four level SC to explore the effects of the main inventory policies; Continuous review $(r, Q)$ in which the replenishment quantity $Q$ is ordered when the inventory position reaches the reorder point $r$, and periodic-review $(T, S)$, in which an order up-to-level $S$ is made for every time period $T$. The study is intended to identify the best inventory policy that provides the best product life cycle. It is concluded that $(r, Q)$ inventory policy provides lower holding quantities but results in higher shortages. Also, it is found that $(T, S)$ in contrast provides higher holding quantities and lower shortages. In [4] the effects of $(r, Q),(T, S)$, Silver-Meal (SM), and part-period balancing (PPB) inventory policies on a two level SC are investigated; one supplier and four retailers. It is found that $(r, Q)$ inventory policy is the best for the retailers and the whole SC but the $(T, S)$ inventory policy and SM are the best for the supplier. In [5] the effects of $(r, Q)$ and $(r, R)$ inventory policies on SC inventory are discussed where $r$ represents the reorder inventory level and $R$ represents the order-up-tolevel. What distinguishes the $(r, R)$ from the $(r, Q)$ is that in $(r, R)$ inventory is replenished on 
item by item or batch by batch basis in which it might take several shipments or production cycles to bring the inventory back to $R$. On the other hand $(r, Q)$ one replenishment quantity $Q$ brings the inventory level back to the target level $Q$. It is found that when $(r, R)$ policy is implemented inventory costs increase as lead times increase while costs do not increase when $(r, Q)$ policy is implemented. Also, the $(r, Q)$ inventory policy always causes lower SC inventory costs than the $(r, R)$ policy.

Many tools are used to analyse SCs, one of the most powerful tools is discrete event simulation. It permits assessment of system performance prior to physical implementation [6]. It also provides solutions to many problems at strategic, operational and tactical levels such as SC design and reconfiguration, inventory planning and management, production scheduling and supplier selection [7-10]. For example, in [9], it is shown that discrete event simulation can be used to design and reconfigure inventory planning and management policies as well as production scheduling and supplier selection in SCs. In [11] simulation was used to improve the efficiency of the distribution level in a catering SC in the Netherlands. A simulation model was developed to explore a multi-compartment distribution system that satisfies customer demand in shorter lead times, increases delivery frequencies and improves quality of processes and products. In [12] simulation was used to explore the effects of a radio frequency identification (RFID) system on inventory updates of a SC. The simulation tool was very effective since it reduced the total inventory costs by $6.19 \%$ and the turnover rate by $7.60 \%$. In [13] a literature review of 127 journals from the year 1996 to 2006 is provided of the application of discrete event simulation in logistics and SC context.

Most previous research concentrates on single product/two level SCs; one supplier and one retailer [4] or one supplier and more than one retailer [14]. Few researchers have studied multi-level SCs with a single product. For instance a simulation model was built to study performance of single product/four echelon SCs; suppliers, manufacturers, distribution centers, and retailers, respectively, under different inventory policies [3]. Also a study was performed on single product/five stage SCs to explore the consequences of the bullwhip effect under different inventory policies [15]. Very little research has been performed to study multilevel/multi-product SCs. In [16] a multi-objective mixed integer nonlinear programming model to optimize certain performance measures for multi-level/multi-product SCs was presented.

The contribution of this work lies in the inclusion and testing of the assignment policy factor and its interactions with other factors such as inventory policies and demand patterns and their effects on SC performance. Many researchers have studied the effects of inventory polices and demand patterns but none to our knowledge have studied the assignment policy factor and its interactions in multilevel/multiproduct SCs using discrete event simulation.

\section{PROBLEM STATEMENT}

This study focuses on the effects of assignment policies of multi-products to limited resources and their interactions with other factors on the performance of multi-level SCs which has not been found in literature. These resources include a production line in the manufacturing level and transportation vehicles responsible for deliveries between various levels of SC. A simulation model of a four-level/three-product SC is developed using Rockwell Arena software [17]. The effects of multi-product assignment rules such as cyclical, preferred and random in combination with various factors such as inventory policies $(r, Q)$ and $(T, S)$ as well as demand patterns with various trends and demand rates are studied. The results of the simulation model are analysed to find the set of parameters that improve on-hand inventory and percentages of satisfied customers at the various levels of the SC. 


\section{CONCEPTUAL SUPPLY CHAIN MODELS}

Fig. 1 shows the SC that is considered in this study. The SC is made up from the following levels: Supplier, Manufacturing plant, Distributor and Retailer. The manufacturing plant contains two buffers; an input buffer for storing raw material and an output buffer for finished goods with a production line in between. Moreover, the SC contains three products; 1, 2, and 3. Many researchers have proposed artificial supply chains in order to test their performance under varying conditions and multiple factors $[5,14,15]$. The usage of artificial supply chains adds value by being less restrictive and more generalizable and can very easily emulate real supply chains by adding certain constraints. In our case, the supply chain used is based on the model found in [18]. The model has been modified to accommodate multiple products as well as various assignment and inventory control policies and demand patterns. It is based on a generic and basic SC with a supplier, manufacturer, distributor and retailer which are the main levels of most real SCs.

When a customer places an order with the retailer, if enough on-hand inventory is present, the customer's demand is fulfilled, otherwise the retailer loses the customer and no backorders are allowed in this level. The distributor and manufacturer follow the same logic except that, if there is not enough on-hand inventory, the unfulfilled demand is backordered. The supplier is assumed to have large inventory levels and can deliver sufficient raw material on request.

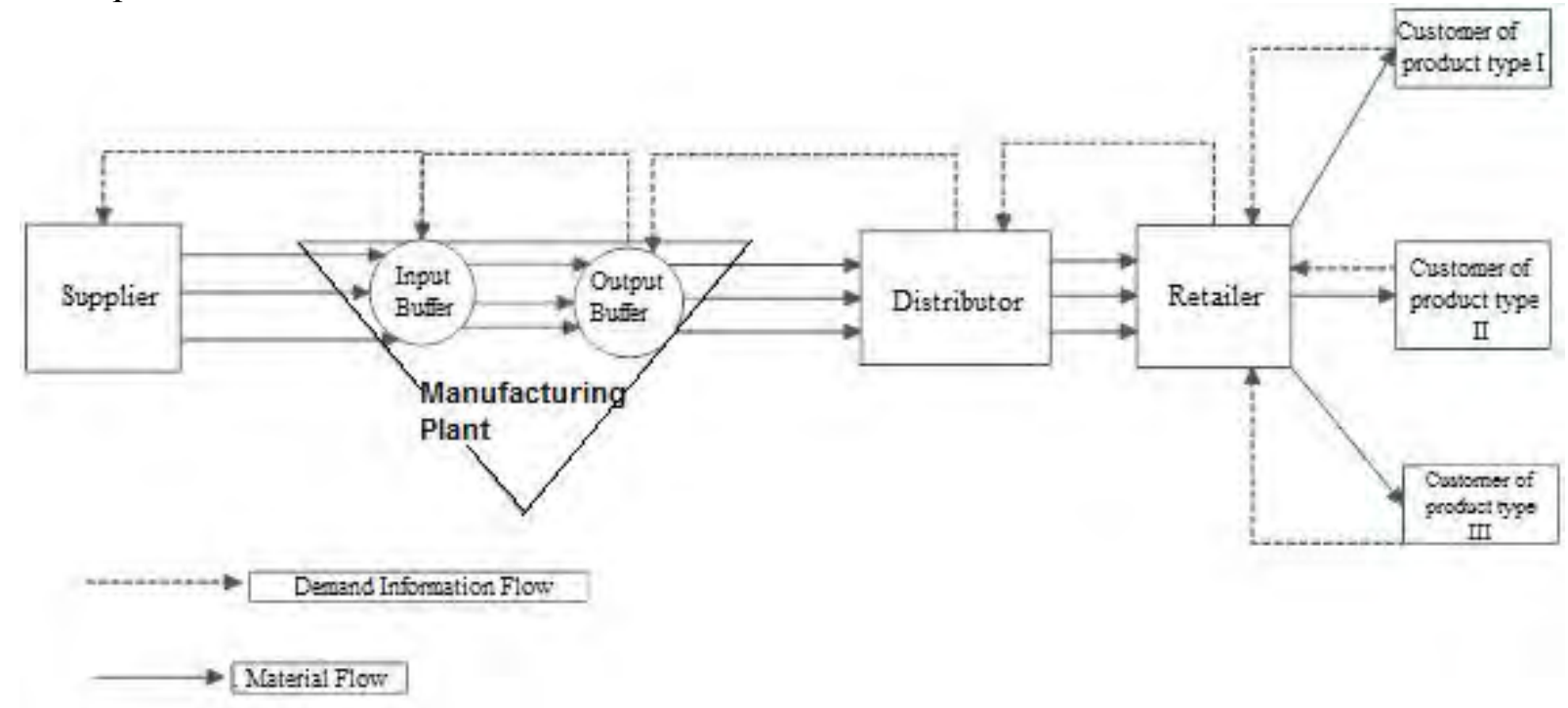

Figure 1: SC conceptual model.

\section{FACTORS}

This study is performed to analyse the effects of three factors on SC performance which are discussed in this section.

\subsection{Assignment policy}

Assignment policies are scheduling and selection rules for customer orders having different attributes and sharing the same resources. When there are multiple orders competing for the same resource with each order being related to a specific product type, the selection of the order that will be fulfilled first is performed based on the different assignment policies; cyclical, preferred, and random, with priorities given to various orders based on the assignment policy used. 
In the cyclical assignment policy, the system will cycle through the three products. The highest priority is first given to product one, then two, then three, and then cycles back to one and so on, the system cycles through the products involved giving them equal chances of being chosen in the long run.

In the preferred assignment the priority is defined based on customized rules. In this study, static priorities are used whereby the highest priority in all SC levels is assigned to product one, then two, with three having the least priority.

With regards to the random policy, the selection of the product is done randomly according to a uniform distribution giving every product equal chances of being selected without regards to which product was selected in previous rounds. This policy is used as a bench mark and reference to the other rules.

\subsection{Inventory control policies}

The focus here is on two inventory policies which are: Continuous review $(r, Q)$ and Periodic review $(T, S)$, also called fixed interval reorder system.

In $(r, Q)$ policy, inventory is continuously monitored and if the inventory level becomes less than or equal to the reorder quantity $r$ a constant order quantity $Q$ is made. Therefore, the main decision variables in this system are $Q$ and $r$ which depend on safety stock considerations in addition to demand rate and lead times. $r$ is calculated using Eq. (1) [19]:

$$
r=\bar{d} \bar{L}
$$

where:

$\bar{d} \quad-$ Average weekly demand,

$\bar{L} \quad$ - Average weekly lead time.

In $(T, S)$ policy, inventory is monitored periodically rather than continuously. For every fixed interval $T$ (time between orders) a quantity $Q$ is ordered which is equal to the difference between the current inventory position level and the target level $S$. The quantity $Q$ is variable in this case. So, the main decision variables in this system are the interval $T$ and the target level $S$. $S$ is calculated using Eq. (2) also based on average weekly demands and lead times [19]:

$$
S=\bar{d} \cdot(T+\bar{L})
$$

\subsection{Demand Patterns}

In practice, the end customer demand is stochastic. Therefore, demand patterns are generated using demand generators such as Eq. (3) [4]:

where:

$$
\text { Demand }_{t}=\text { base }+ \text { slope } \times t+\text { season } \times \sin \left(\frac{2 \pi}{\text { Season cycle }} t\right)+\text { noise } \times \operatorname{snormal}()
$$

Demand $\mathrm{t}_{\mathrm{t}}$ is the demand on day $t(t=1,2,3, \ldots, 410)$, snormal( ) is the standard normal random variate generator, Season cycle $=7$ for demand varying weekly.

The other parameters; base, slope, season and noise define the characteristics of the demand generators. They are selected from [4] to insure that the average customer order size is 1000 units. The demand generators contain different variations of trends, seasonalities and noise components. In this study, the focus is on two demand patterns which are ILI (low seasonality, low positive trend) and IHD (high seasonality, high negative trend). 


\section{MODEL ASSUMPTIONS AND DATA}

The system is subjected to the following assumptions:

- The three products are subjected to the same conditions with the same inventory control parameters.

- For the three products, customer interarrival times are exponentially distributed with multiple means.

- An order is related to one specific product only.

- All the SC levels use the same inventory and assignment policy in a single simulation run.

- The batch production time at manufacturing level is represented by the Erlang distribution $\operatorname{Erl}(k=3)$ with multiple means.

- The manufacturing plant level implements the $(r, R)$ inventory policy between the input and output buffer.

- Orders are manufactured in batches which are chosen to be a multiple of both $r$, and $R$ and always less than or equal to $R$.

- There is only one production line in the manufacturer level that can produce the three types of products. Each product order is manufactured fully before a different type product order is released. No mix in products is allowed on the production line.

- The transportation time between SC levels is represented by the Erlang distribution $\operatorname{Erl}(k=$ 2) with multiple means.

- Two transportation trucks are available between any two consecutive levels. An order shipment is only launched after the previous one is received at destination. An order is shipped as a whole in one trip. Because of this restriction on the shipment of orders as a whole, constraints are put on the order quantities and target levels as follows to prevent partial orders from being shipped between levels:

○ when $(r, Q)$ inventory policy is implemented:

$$
Q_{-} \text {Retailer } \leq Q_{-} \text {Distributor } \leq R_{-} \text {output buffer } \leq Q_{-} \text {Input buffer }
$$

o when $(T, S)$ inventory policy is used, computed target levels are restricted as follows: $S \_$retailer $\leq S \_$Distributor $\leq R \_$output buffer $\leq S \_$Input buffer

- The replication length is 410 days.

- The warm-up period is 1 week.

- One unit of finished product needs one unit of raw material to be produced.

\section{PERFORMANCE MEASURES}

Generally, various key performance indicators (KPIs) are used to assess the efficiency of a SC, some are cost based, while others are based on service levels. Cost related KPIs include inventories carrying costs, order setup costs and shipping costs. On the other hand, KPIs related to service levels are usually based on the percentage of satisfied customers and the average number of lost customers. Other service related KPIs include the average number and quantity of back orders and on hand inventories levels.

In this study, the KPIs that are used to assess the SC performance are the amount of onhand inventories for the retailer, distributor and manufacturer output buffer as well as the percentage of lost customers at retailer and percentage of customer satisfaction at distributor and output buffer. Percentage of satisfaction is computed by dividing the number of satisfied orders by the overall number of orders at a certain level. Satisfied orders are the ones that are immediately fulfilled once placed. Percentage of lost orders is computed similarly. 


\section{ANOVA RESULTS AND INTERACTIONS BETWEEN FACTORS}

The analysis of variance (ANOVA) technique is used to analyse the main and interaction effects of the factors considered, a full factorial design is implemented with three levels for assignment policies and two levels for inventory policies and demand patterns. 12 scenarios are tested as shown in Table I with each scenario implemented in a separate simulation model. Twenty independent replicates were run for each scenario, which resulted in 240 data points for each performance measure per product per SC level.

Table I: Simulation runs.

\begin{tabular}{|c|l|l|l|}
\hline Run & Assignment policy & Inventory Policy & Demand Pattern \\
\hline 1 & Cyclical & $(T, S)$ System & IHD \\
\hline 2 & Cyclical & $(T, S)$ System & ILI \\
\hline 3 & Cyclical & $(r, Q)$ system & IHD \\
\hline 4 & Cyclical & $(r, Q)$ system & ILI \\
\hline 5 & Preferred & $(T, S)$ System & IHD \\
\hline 6 & Preferred & $(T, S)$ System & ILI \\
\hline 7 & Preferred & $(r, Q)$ system & IHD \\
\hline 8 & Preferred & $(r, Q)$ system & ILI \\
\hline 9 & Random & $(T, S)$ System & IHD \\
\hline 10 & Random & $(T, S)$ System & ILI \\
\hline 11 & Random & $(r, Q)$ system & IHD \\
\hline 12 & Random & $(r, Q)$ system & ILI \\
\hline
\end{tabular}

The simulation was run for the 12 scenarios using base parameter values described in the next section. ANOVA residual plots were used to check the quality of the performed statistical analysis. The plots are approximately straight, therefore, the residuals are normally distributed and the normality assumption is valid. The residual histograms also confirm normality. In addition, the plots of residuals versus fitted values show that there are no recognizable patterns. The plots do not show a series of increasing or decreasing points, a predominance of positive residuals, or a predominance of negative residuals and patterns, such as increasing residuals with increasing fits. Therefore the model is adequate for the analysis.

Results are shown in Table II which shows the p-values of on-hand inventories for three $\mathrm{SC}$ levels and three products where numbers in bold represent insignificance. The table shows that the assignment policy factor $(A)$ is mostly insignificant except for product 1 at retailer and distributor levels. The inventory policy factor $(B)$ was found to be significant for all levels and products while the demand pattern factor $(C)$ was mostly significant except for the three products in the manufacturer output buffer. As far as interactions between factors the table shows that at manufacturer output buffer all interactions were insignificant. Also, the assignment policy and demand pattern interaction are mostly insignificant at all levels and products except for product 1 at retailer. Assignment and inventory policies interactions were significant for products 1 and 3 in both retailer and distributor levels.

The simulation was also run for all scenarios while increasing the demand rate to 100 instead of 10 in the previous case using base values. Results show that three factors become significant with the inventory policy factor still being the most significant. Interactions $A B$, $A C$ and $B C$ are also significant in this case. 
Al-Hawari, Ahmed, Khrais, Mumani: Impact of Assignment, Inventory Policies and ...

Table II: ANOVA $p$-values for on-hand inventory of three products in three SC levels.

\begin{tabular}{|l|c|c|c|c|c|c|c|c|c|}
\hline Source & OH DC 1 & OH DC 2 & OH DC 3 & $\begin{array}{l}\text { OH } \\
\text { Output } \\
\text { buffer 1 }\end{array}$ & $\begin{array}{l}\text { OH } \\
\text { Output } \\
\text { buffer 2 }\end{array}$ & $\begin{array}{l}\text { OH } \\
\text { Output } \\
\text { buffer 3 }\end{array}$ & $\begin{array}{l}\text { OH } \\
\text { Retailer1 }\end{array}$ & $\begin{array}{l}\text { OH } \\
\text { Retailer2 }\end{array}$ & $\begin{array}{l}\text { OH } \\
\text { Retailer3 }\end{array}$ \\
\hline Model & $<0.0001$ & $<0.0001$ & $<0.0001$ & $<0.0001$ & $<0.0001$ & $<0.0001$ & $<0.0001$ & $<0.0001$ & $<0.0001$ \\
\hline $\begin{array}{l}\text { A-Assignment } \\
\text { Policy }\end{array}$ & $<0.0001$ & $\mathbf{0 . 8 3 9 5}$ & $\mathbf{0 . 1 8 8 9}$ & $\mathbf{0 . 3 2 1 3}$ & $\mathbf{0 . 3 6 8 5}$ & $\mathbf{0 . 0 8 8 7}$ & 0.0022 & $\mathbf{0 . 3 5 4 6}$ & $\mathbf{0 . 3 9 0 6}$ \\
\hline $\begin{array}{l}\text { B-Inventory } \\
\text { Policy }\end{array}$ & $<0.0001$ & $<0.0001$ & $<0.0001$ & $<0.0001$ & $<0.0001$ & $<0.0001$ & $<0.0001$ & $<0.0001$ & $<0.0001$ \\
\hline $\begin{array}{l}\text { C-Demand } \\
\text { Pattern }\end{array}$ & $<0.0001$ & $<0.0001$ & $<0.0001$ & $\mathbf{0 . 8 4 6 9}$ & $\mathbf{0 . 2 6 1 9}$ & $\mathbf{0 . 9 4 1 0}$ & $<0.0001$ & $<0.0001$ & $<0.0001$ \\
\hline AB & 0.0251 & $\mathbf{0 . 8 0 7 7}$ & 0.0080 & $\mathbf{0 . 1 1 2 1}$ & $\mathbf{0 . 3 6 5 6}$ & $\mathbf{0 . 2 6 1 8}$ & 0.0070 & $\mathbf{0 . 9 5 8 7}$ & 0.0118 \\
\hline AC & $\mathbf{0 . 0 5 6 1}$ & $\mathbf{0 . 6 5 9 8}$ & $\mathbf{0 . 2 7 4 2}$ & $\mathbf{0 . 0 5 8 2}$ & $\mathbf{0 . 5 3 9 9}$ & $\mathbf{0 . 8 8 1 7}$ & 0.0191 & $\mathbf{0 . 9 7 7 6}$ & $\mathbf{0 . 7 1 0 6}$ \\
\hline BC & $<0.0001$ & $<0.0001$ & $<0.0001$ & $\mathbf{0 . 8 5 9 5}$ & $\mathbf{0 . 5 7 5 7}$ & $\mathbf{0 . 7 0 0 7}$ & $<0.0001$ & $<0.0001$ & $<0.0001$ \\
\hline ABC & $\mathbf{0 . 4 7 1 1}$ & $\mathbf{0 . 4 2 6 0}$ & $\mathbf{0 . 8 2 9 6}$ & $\mathbf{0 . 3 0 5 3}$ & $\mathbf{0 . 7 2 1 3}$ & $\mathbf{0 . 7 3 6 1}$ & $\mathbf{0 . 7 1 3 8}$ & $\mathbf{0 . 2 2 8 0}$ & $\mathbf{0 . 2 9 4 0}$ \\
\hline
\end{tabular}

Fig. 2 shows a sample of the interaction plots for the retailer's on-hand inventory for product 1 for a demand rate of 10. Part $a$ of the figure shows the inteaction between the assigment and inventory policies which indicates clearly that regardless of the assignmnent policy the $(T, S)$ inventory system results in higher on hand inventory. Part $b$ shows the interaction between the assignment policy and demand pattern which indicates that the preferred and cyclical assignment policies asociated with IHD demand pattern results in lower on hand inventory than the combination of these policies with ILI. Part $c$ shows the interaction between inventory policy and demand pattern which indicates that the $(r, Q)$ system results in lower on hand inventory regardless of the demand pattern used.
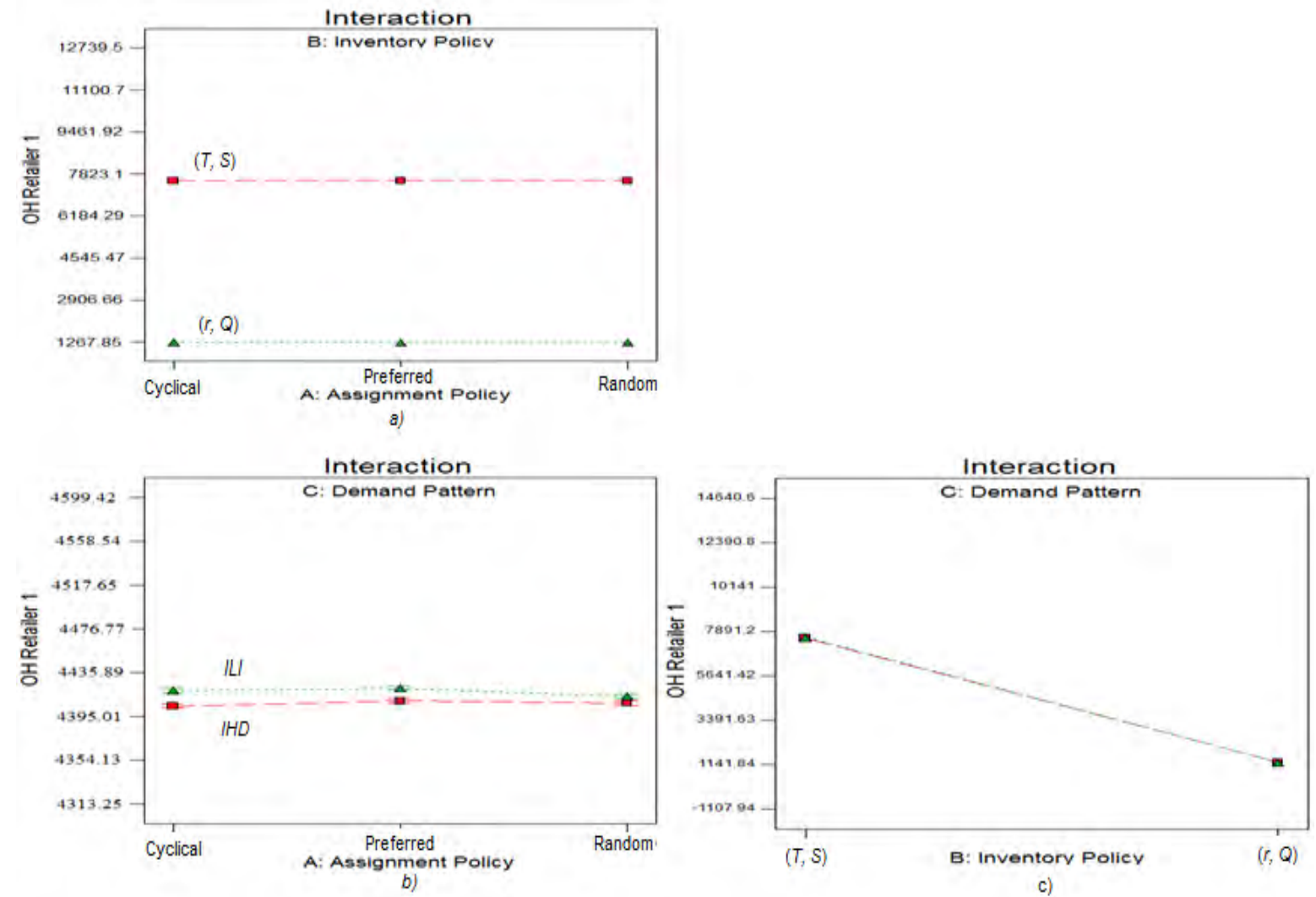

Figure 2: Sample of interaction plots for Product One's Retailer on-hand inventory. 


\section{SENSITVITY ANALYSIS}

Sensitivity analysis is conducted on a range of corresponding input parameters depending on the factors used. When $(r, Q)$ inventory policy is implemented, input parameters tested in the different SC levels are shown in Table III. These parameters are changed one at a time while all other parameters are fixed at the base values of retailer's $Q$ of 2000 units, distributor's $Q$ of 4000 units, output buffer's $r$ and $R$ of 8000 and 10000 units, respectively, manufacturing batch size of 2000 units, input buffer's $Q$ of 12000 units, demand rate of 10 customers per hour and all exponential means of transportation and manufacturing delays of $0.1 \mathrm{hr}$. On the other hand, for $(T, S)$ inventory policy, input parameters tested are shown in Table IV. Similarly, these parameters are changed one at a time while all other parameters are fixed at the base values of $T$ of $2 \mathrm{hrs}$ for all levels, all exponential means of transportation and manufacturing delays of $0.01 \mathrm{hr}$ with all other base parameters being equal to the previous case. In both cases, tested parameters for the manufacturing plant level are shown in Table V.

Table III: $(r, Q)$ tested input parameters.

\begin{tabular}{|l|c|c|c|c|}
\hline$Q \_$Retailer (units) & 2000 & 3000 & 4000 & \\
\hline$Q \_$Distributor (units) & 2000 & 4000 & 6000 & 8000 \\
\hline$Q \_$Input buffer (units) & 12000 & 16000 & 20000 & \\
\hline Demand Rate (cust/hr) & 10 & 100 & & \\
\hline $\begin{array}{l}\text { Exponential Mean of Transportation } \\
\text { delay Erl (k=2) (hr) }\end{array}$ & 0.01 & 0.05 & 0.1 & \\
\hline $\begin{array}{l}\text { Exponential Mean of Manufacturing } \\
\text { delay Erl (k=3) (hr) }\end{array}$ & 0.01 & 0.05 & 0.1 & \\
\hline
\end{tabular}

Table IV: $(T, S)$ tested input parameters.

\begin{tabular}{|l|c|c|c|}
\hline$T$ retailer (hr) & 2 & 4 & 6 \\
\hline$T$ Distributor (hr) & 2 & 4 & 6 \\
\hline$T$ Input buffer (hr) & 2 & 4 & 6 \\
\hline Demand Rate (customer/hr) & 10 & 100 & \\
\hline $\begin{array}{l}\text { Exponential Mean of Trans. delay } \\
\text { Erl(k=2) (hr) }\end{array}$ & 0.01 & 0.05 & 0.1 \\
\hline $\begin{array}{l}\text { Exponential Mean of Manu. delay } \\
\text { Erl(k=3) (hr) }\end{array}$ & 0.01 & 0.05 & 0.1 \\
\hline
\end{tabular}

Table V: Manufacturing plant tested input parameters.

\begin{tabular}{|l|c|c|c|}
\hline Output buffer $r$ (units) & 4000 & 6000 & 8000 \\
\hline Output buffer $R$ (units) & 10000 & 12000 & \\
\hline
\end{tabular}

Table VI shows the results of the sensitivity analysis in which a plus sign indicates a positive trend, a minus sign indicates a negative trend, while run numbers on which the sensitivity analysis was implemented shown in the first column are taken from Table I. In 
general the results show the relationship between on-hand inventory and percentage of satisfied or lost customers at the various levels of SC. As on-hand inventory increases, the percentage of satisfied customers also increases because the chances of customers coming and not finding their orders is minimized because lead times are minimized which also decreases the percentage of lost orders.

Table VI: Sensitivity analysis trends.

\begin{tabular}{|c|l|c|c|c|c|c|c|}
\hline Runs & Parameter Varied & $\begin{array}{c}\% \text { lost } \\
\text { Retailer }\end{array}$ & $\begin{array}{c}\% \text { Sat. } \\
\text { DC }\end{array}$ & $\begin{array}{c}\% \text { Sat. } \\
\text { Output } \\
\text { buffer }\end{array}$ & $\begin{array}{c}\text { OH } \\
\text { Retailer }\end{array}$ & OH DC & $\begin{array}{c}\text { OH } \\
\text { Output } \\
\text { buffer }\end{array}$ \\
\hline $1,5,9$ & Tincreased from 2 to 6 & + & - & - & - & - & + \\
\hline $1,5,9$ & $\begin{array}{l}\text { Output buffer } r \text { increased } \\
\text { from 4000 to 8000 }\end{array}$ & - & + & $\begin{array}{c}\text { No } \\
\text { trend }\end{array}$ & + & + & + \\
\hline $1,5,9$ & $\begin{array}{l}\text { Output buffer } R \text { increased } \\
\text { from 10000 to 12000 }\end{array}$ & $\begin{array}{c}\text { No } \\
\text { trend }\end{array}$ & $\begin{array}{c}\text { No } \\
\text { trend }\end{array}$ & $\begin{array}{c}\text { No } \\
\text { trend }\end{array}$ & $\begin{array}{c}\text { No } \\
\text { trend }\end{array}$ & $\begin{array}{c}\text { No } \\
\text { trend }\end{array}$ & + \\
\hline $1,5,9$ & $\begin{array}{l}\text { Demand Rate increased from } \\
\text { 10 to 100 }\end{array}$ & + & - & + & - & - & + \\
\hline $1,5,9$ & $\begin{array}{l}\text { Exponential Mean of Trans. } \\
\text { and Manu. Delay }\end{array}$ & $\begin{array}{c}\text { No } \\
\text { trend }\end{array}$ & $\begin{array}{c}\text { No } \\
\text { trend }\end{array}$ & $\begin{array}{c}\text { No } \\
\text { trend }\end{array}$ & - & - & - \\
\hline $3,7,11$ & $\begin{array}{l}Q \quad \text { Retailer increased from } \\
\text { 2000 to 4000 }\end{array}$ & - & - & $\begin{array}{c}\text { No } \\
\text { trend }\end{array}$ & + & - & - \\
\hline $3,7,11$ & $\begin{array}{l}Q \quad \text { Distributor increased from } \\
\text { 2000 to 8000 }\end{array}$ & - & $\begin{array}{c}\text { No } \\
\text { trend }\end{array}$ & $\begin{array}{c}\text { No } \\
\text { trend }\end{array}$ & $\begin{array}{c}\text { No } \\
\text { trend }\end{array}$ & + & - \\
\hline $3,7,11$ & $\begin{array}{l}Q \quad \text { Input buffer increased } \\
\text { from 12000 to 20000 }\end{array}$ & $\begin{array}{c}\text { No } \\
\text { trend }\end{array}$ & $\begin{array}{c}\text { No } \\
\text { trend }\end{array}$ & $\begin{array}{c}\text { No } \\
\text { trend }\end{array}$ & $\begin{array}{c}\text { No } \\
\text { trend }\end{array}$ & $\begin{array}{c}\text { No } \\
\text { trend }\end{array}$ & + \\
\hline $3,7,11$ & $\begin{array}{l}\text { Output buffer } R \text { increased } \\
\text { from 10000 to 12000 }\end{array}$ & $\begin{array}{c}\text { No } \\
\text { trend }\end{array}$ & $\begin{array}{c}\text { No } \\
\text { trend }\end{array}$ & $\begin{array}{c}\text { No } \\
\text { trend }\end{array}$ & $\begin{array}{c}\text { No } \\
\text { trend }\end{array}$ & $\begin{array}{c}\text { No } \\
\text { trend }\end{array}$ & + \\
\hline $3,7,11$ & $\begin{array}{l}\text { Demand Rate increased from } \\
\text { 10 to 100 }\end{array}$ & + & - & $\begin{array}{c}\text { No } \\
\text { trend }\end{array}$ & - & - & - \\
\hline
\end{tabular}

In $(T, S)$ systems in general, the increase of the time period $T$ would normally lead to an increase in the target level $S$ according to Eq. (2) which would minimize shortages in inventory between orders. In this case, the increase in $T$ led to a decrease in on-hand inventory in both the retailer and distributor levels which led to decreased customer satisfaction and increased lost orders. This is an indication that on-hand inventory was not enough to meet the demand for the longer periods in these levels. The main reason for this is the upper limit imposed on $S$ in the simulation model in these levels, due to the assumption that an order is shipped as a whole in one trip and cannot be divided into several shipments. This assumption restricted $S$ as described previously in Section 5. This means that the target levels of both the retailer and distributor required maintaining higher customer satisfactions were not met. In the sensitivity analysis an additional constraint was imposed on the target level $S$ of the distributor which was maintained below the output buffer's $r$ which is not a strict constraint and was included for testing purposes. This constraint explains the increase in on-hand inventory in the three SC levels shown associated with the increase in $r$. On the other hand, when the target level of the output buffer output buffer $R$ is increased no trends were observed on the on-hand inventory levels in both retailer and distributor. This is also a direct result of this constraint, which makes the distributor and retailer levels less sensitive to the target level $R$ of the output buffer. Only on-hand inventory in output buffer is increased in this case. An increase in customer demand rates at retailer from 10 to 100 customers per hour led to a decrease in on-hand inventory in both retailer and distributor. This is also due to the limit imposed on $S$ in these levels, which led to a shortage in inventory that could not meet the 
increased demand. On the other hand, on-hand inventory in the output buffer increased which shows that the target level $R$ of the output buffer is enough to meet demand and satisfy customers. Increased means of both transportation and manufacturing delays led to a decrease in inventory in retailer, distributor and output buffer. For the same demand rate this is expected because fewer inventories would be supplied within the same time period.

In $(r, Q)$ systems in general, an increase in order quantity $Q$ at a specific level in SC would increase on-hand inventory at that level and affect other levels as well. For example, when the retailer's $Q$ increased from 2000 to 4000 units, on-hand inventory at retailer increased, while on-hand inventory at both distributor and output buffer decreased. With all factors held constant, increasing the order quantity at one level would increase order sizes from upstream levels consecutively which puts pressure on upstream resources. If these upstream levels do not respond to this increase in demand with their own increase in order sizes then this would lead to reduced on-hand inventories at these levels. On the other hand, downstream levels, would not suffer from such shortages because enough inventory is present from their supplier; the level in which the increase in order size has occurred. This can be noticed from the results which show how an increase in one level's $Q$ would lead to a decrease in upstream levels on-hand inventories while maintaining the same inventories levels in downstream levels. This is noticed from increasing retailer's $Q$, distributor's $Q$, target of output buffer $R$, and input buffer $Q$. The results show clearly how the effect of increasing $Q$ in one level is transformed to upstream and downstream levels. Upstream levels are all negatively affected, while downstream levels maintain the same levels of inventory without any noticeable trends. The increase in customer demand rates at retailer from 10 to 100 in $(r$, $Q)$ systems led to the same results obtained in $(T, S)$ systems with decreased inventories at both retailer and distributor with the exception of output buffer inventory levels which also decreased. This indicates that all order quantities in these levels are short of satisfying the increase in demand and should all be increased accordingly. This is true because the retailer and distributor $Q$ s were all set to values less than the target levels computed in $(T, S)$ system which was limited by the output buffer's $r$ of 8000 units. The reason why on-hand inventory in the output buffer also decreased in this case can be attributed to the decrease in input buffer's order quantity which is set to a value well below the value of the target computed in the $(T, S)$ system. This means that the manufacturing plant took more time to manufacture the same quantity because of shortages in raw material in the input buffer.

Sensitivity analysis confirms the ANOVA results of the previous section as it is noticed that results are independent of the assignment policy but dependent on both inventory and demand patterns. This confirms the insignificance of the assignment policy at low demand rates for all scenarios tested.

Fig. 3 shows the average on-hand inventories of the three products in the retailer, distributor and output buffer in the $(T, S)$ system against the tested input parameters for the three assignment policies. The figure shows the robustness of the results and the trends identified previously. It shows clearly how the increase in $T$ led to a decrease in on-hand inventory at retailer and distributor. The effect of the limit on the retailer's and distributor's $S$ is clearly shown by the first downward spike at a value of 4000 units for output buffer's $r$. This effect is gradually lessened as this limit is relieved. The other spike happens at the 100 demand rate point which reduces the inventory considerably at retailer and distributor and again shows the effect of the limit on $S$ in these levels. Because the figure shows average inventories of the three products, assignment policies' effects are not shown.

Fig. 4 shows the average on-hand inventories of the three products in the retailer, distributor and output buffer in the $(r, Q)$ system against the tested input parameters for the three assignment policies. It shows clearly how an increase in order quantity $Q$ at a specific level in SC would increase on-hand inventory at that level while decreasing on-hand 
inventory in upstream levels and maintaining the same levels in downstream levels. This result is more clearly seen between retailer and distributor and to a lesser extent with the output buffer.

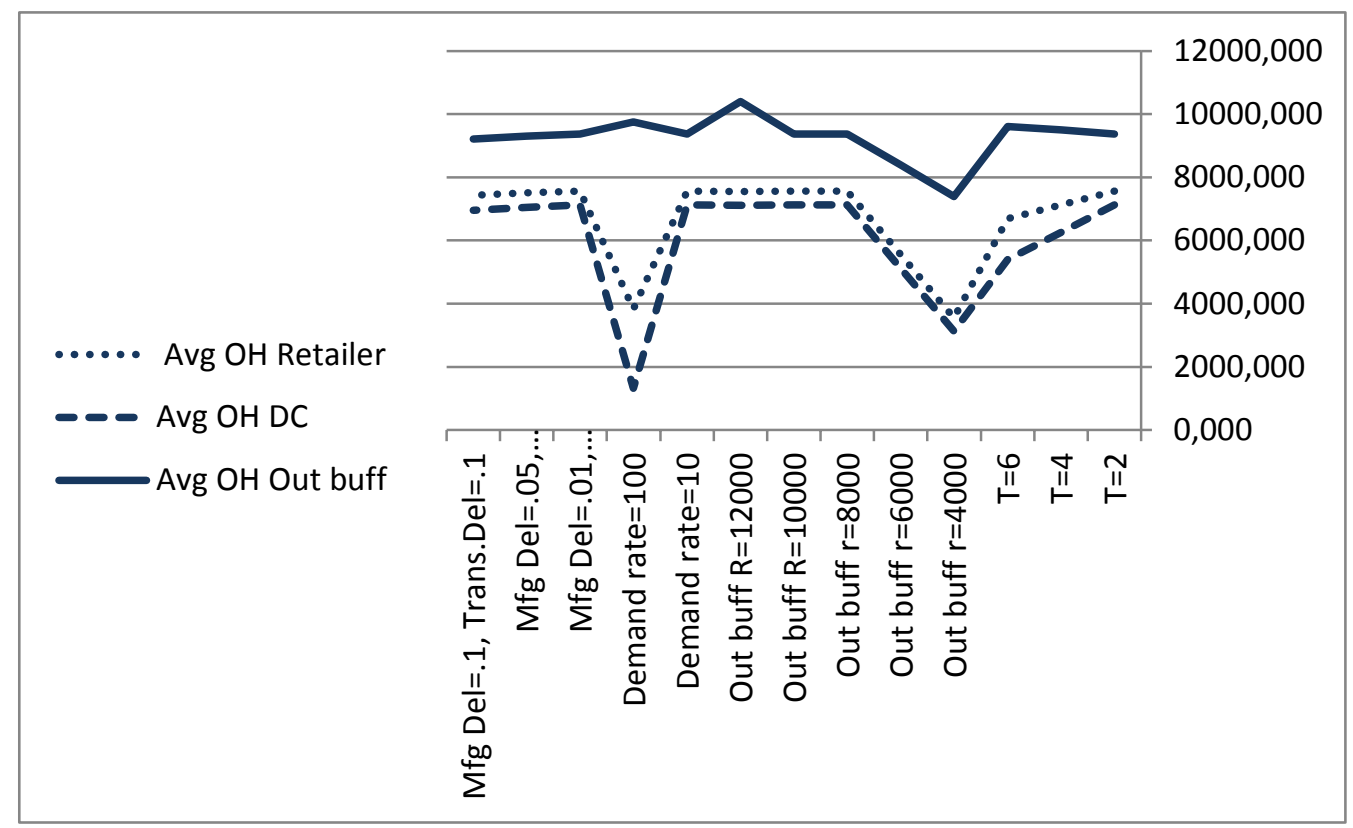

Figure 3: Average on-hand inventories for three products in $(T, S)$ system.

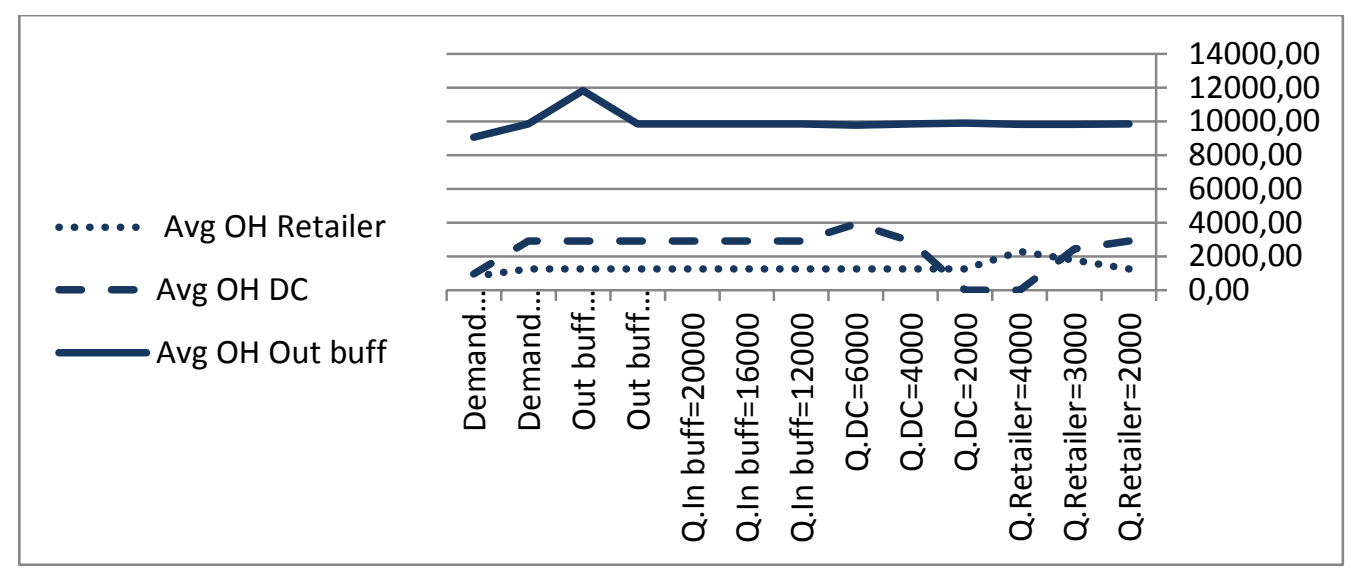

Figure 4: Average on-hand inventories for three products in $(r, Q)$ system.

Assignment policies effects are shown on a product by product basis. Fig. 5 a shows onhand inventory levels for the three products in three levels of SC when the preferred assignment policy is used with $(r, Q)$ system with a demand rate of 10 and base values for the other parameters in the model. It is clear from the figure that the level of inventory is determined by the value of $Q$ in both retailer and distributor and the value of $R$ in the output buffer. Although the preferred policy is used which gives priority to the first product, its effect is not evident in this case on the levels of inventories of the three products in each level which are almost the same which confirms previous ANOVA results. This can be attributed to low overall traffic intensities at this demand rate which was computed by the model and did not exceed 0.188 in any level of SC.

To ascertain this, another run was made on the same model while increasing the demand rate to 100 and keeping all other parameters the same. Fig. $5 \mathrm{~b}$ shows the results of this run, which clearly shows the differences between the three products. It is noticed that in both 
retailer and distributor, product 1 has the highest level, then 2 and then 3 while in output buffer the order is reversed. The effect of the assignment policy is evident in the results when the system is under pressure with increased traffic intensities which also confirms the significance of this factor when demand rates are increased. The distributor in this case is heavily loaded with traffic intensity close to 1 , while the output buffer is still under loaded with a traffic intensity of 0.29 . The reason behind the reversal in order of the levels in on-hand inventory in the output buffer can be attributed to the loading intensity of each level. In the output buffer, under loading led to low lead times through the manufacturer for the three products having almost identical lead times of about $0.21 \mathrm{hrs}$ without regard to the priorities imposed. It is noticed that the backorders at this level are almost zero which indicates the capacity of the manufacturer meets the demand with almost $99 \%$ customer satisfaction. The preferred assignment policy tends to increase demand on higher priority items. This led to a higher withdrawal rate on higher priority items from the distributor than the replenishment rate of the manufacturer with a high target that tended to level out the quantities produced. This led to decreasing quantities at the manufacturer with increased product priorities. On the other hand, lead times between the distributor and retailer gradually increased from 0.48 , 0.62 , to $0.88 \mathrm{hrs}$ as the priority of the product decreased. It is noticed at this level that backorders increase with decreased priority with an average of 143, 366, and 877 units for products 1, 2 and 3, respectively. Replenishment rate of high priority products was more than the withdrawal rate because of the difference in order quantities which led to increased inventory for higher priority products and increased customer satisfaction that ranged from 78 $\%$ for product 1 to $64 \%$ for product 3 . In conclusion, the higher the target level or order size, the less the traffic intensity, the less the effect of the assignment policy on on-hand inventories and customer satisfaction.

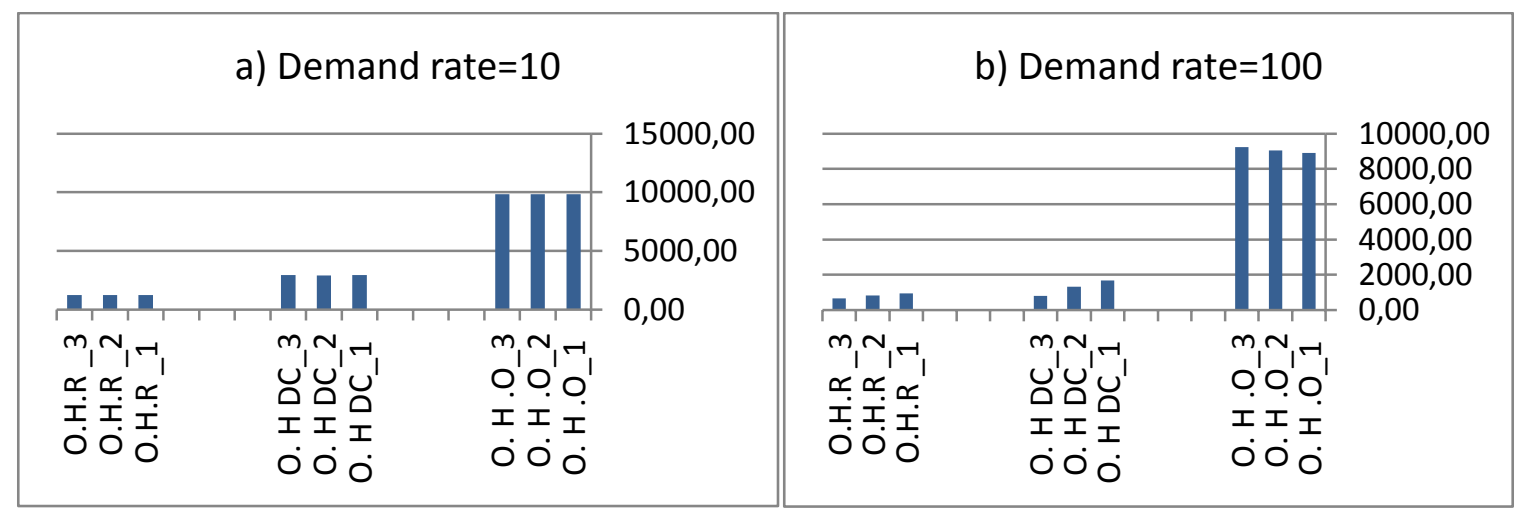

Figure 5: On-hand inventories, preferred, $(r, Q)$.

In the $(T, S)$ system, on-hand inventory levels of the three products were almost identical in each level of SC with the preferred assignment policy because the system was under loaded with traffic intensities not exceeding 0.23 at a demand rate of 100. This is due to the higher targets computed for the retailer and distributor.

When the cyclical and random assignment policies were used, no distinct differences were noticed in on-hand inventory levels of the three products at the various SC levels with both $(r, Q)$ and $(T, S)$ systems at demand rates 10 and 100 .

As far as the demand patterns are concerned, all 12 scenarios were run using two demand rates 10 and 100 on the base values of the parameters of each model. Results show that the IHD pattern results in higher percentages of lost orders than the ILI pattern. This is expected because the positive trend in the IHD patterns tends to increase the load on resources over time; this effect is more evident in a heavily loaded system than a lightly loaded one. 


\section{CONCLUSION}

In general, the results show that as on-hand inventory increases, the percentage of satisfied customers increases because lead times are minimized, which reduces waiting times for order fulfilments and also leads to a decrease in percentage of lost customers. In $(T, S)$ systems in general, it is found that imposing an upper limit on $S$ in some SC levels due to the assumption that an order is shipped as a whole in one trip would greatly influence results. Consequently, an increase in $T$ not associated with a sufficient increase in $S$ would decrease inventory levels that would lead to shortages between orders. Imposing a limit on $S$ in a level by the reorder point of an adjacent upstream level would make this level act as a barrier between downstream and upstream levels. So an increase in the target of one upstream level would not affect the level of inventory in downstream levels greatly. Additionally, an increase in customer demand rates led to a decrease in on-hand inventory in the levels with limited $S$. Also, an increase in means of both transportation and manufacturing delays led to a decrease in inventory in all levels due to increased lead times. In $(r, Q)$ systems in general, the results show clearly how the effect of increasing $Q$ in one level is transformed to upstream and downstream levels. Upstream levels are all negatively affected, while downstream levels maintain the same levels of inventory without any noticeable trends. Similar to $(T, S)$ systems an increase in demand rates decreased inventories at levels with low targets.

ANOVA results show that at low demand rates inventory policies are the most significant, then demand patterns while assignment policies are insignificant. At high demand rates the assignment policy factor becomes significant as well as the other two factors. As far as interactions between factors it is shown that at low demand rates the inventory policy and demand pattern interactions are mostly significant while other interactions are mostly insignificant. All interactions are significant at high demand rates with the assignment and inventory policies interactions being the most significant.

Sensitivity analysis performed shows the robustness of the results under varying conditions. In general, it is shown that assignment policies' effects are not evident at low demand rates and traffic intensities. Their effects are more recognizable when demand rates increase and systems are put under pressure with high traffic intensities.

Future work would involve testing a mix of assignment policies, inventory systems and demand patterns simultaneously in the SC. Other assignment policies can be tested especially dynamic preferred policies that prioritize orders based on shared information between SC levels. These priorities can be made dynamic by relating them to certain performance measures in the SC such as percentage of lost orders or satisfied customers from a certain product in downstream levels or to the product with least on-hand inventory or highest backorders. Dynamic priorities require information sharing between SC levels which depend on company policies that might allow or restrict sharing of such information. Additionally, other distributions can be tested to represent both manufacturing and transportation delays and the effects of change in variability can be addressed. The capacities of the various resources can also become an extra factor. The limitation in transporting orders as one single shipment can be removed and the model rebuilt on this new assumption. Finally, other performance measures can be used such as cost based measures to strengthen the results.

\section{REFERENCES}

[1] Chan, F. T. S.; Tang, N. K. H.; Lau, H. C. W.; Ip, R. W. L. (2002). A simulation approach in supply chain management, Integrated Manufacturing Systems, Vol. 13, No. 2, 117-122, doi:10.1108/09576060210415455

[2] Terzi, S.; Cavalieri, S. (2004). Simulation in the supply chain context: a survey, Computers in Industry, Vol. 53, No. 1, 3-16, doi:10.1016/S0166-3615(03)00104-0 
[3] Chen, S. (2010). A Study on performance of inventory policies in a multi-stage supply chain system, Chaoyang University of Technology, Taiwan

[4] Lau, R. S. M.; Xie, J.; Zhao, X. (2008). Effects of inventory policy on supply chain performance: A simulation study of critical decision parameters, Computers \& Industrial Engineering, Vol. 55, No. 3, 620-633, doi:10.1016/j.cie.2008.02.002

[5] Liao, T. W.; Chang, P. C. (2010). Impacts of forecast, inventory policy, and lead time on supply chain inventory - A numerical study, International Journal of Production Economics, Vol. 128, No. 2, 527-537, doi:10.1016/j.ijpe.2010.07.002

[6] Al-Hawari, T.; Aqlan, F.; Al-Araidah, O. (2010). Performance analysis of an automated production system with queue length dependent service rates, International Journal of Simulation Modelling, Vol. 9, No. 4, 184-194, doi:10.2507/IJSIMM09(4)2.168

[7] Chopra, S.; Meindl, P. (2005). Supply Chain Management: Strategy, Planning and Operations, Prentice Hall College Div, New York

[8] Copacino, W. C. (1997). Supply Chain Management: The Basics and Beyond, CRC Press, Falls Church

[9] Koutsoukis, N.-S.; Dominguez-Ballesteros, B.; Lucas, C. A.; Mitra, G. (2000). A prototype decision support system for strategic planning under uncertainty, International Journal of Physical Distribution \& Logistics Management, Vol. 30, No. 7/8, 640-661, doi:10.1108/ 09600030010346387

[10] Simchi-Levi, D; Kaminsky, P.; Simchi-Levi, E. (2007). Designing and Managing the Supply Chain, McGraw-Hill/Irwin, New York

[11] Jansen, D. R.; van Weert, A.; Beulens, A. J. M.; Huirne, R. B. M. (2001). Simulation model of multi-compartment distribution in the catering supply chain, European Journal of Operational Research, Vol. 133, No. 1, 210-224, doi:10.1016/S0377-2217(00)00204-6

[12] Wang, S.-J.; Liu, S.-F.; Wang, W.-L. (2008). The simulated impact of RFID-enabled supply chain on pull-based inventory replenishment in TFT-LCD industry, International Journal of Production Economics, Vol. 112, No. 2, 570-586, doi:10.1016/j.ijpe.2007.05.002

[13] Tako, A. A.; Robinson, S. (2012). The application of discrete event simulation and system dynamics in the logistics and supply chain context, Decision Support Systems, Vol. 52, No. 4, 802-815, doi:10.1016/j.dss.2011.11.015

[14] Lee, H. T.; Wu, J. C. (2006). A study on inventory replenishment policies in a two-echelon supply chain system, Computers \& Industrial Engineering, Vol. 51, No. 2, 257-263, doi:10.1016/j.cie.2006.01.005

[15] Li, Y. Z.; Zhang, X. D. (2011). Dynamic modeling and simulation on ordering strategy of fivestage supply chain, Advanced Materials Research, Vol. 267, 372-376, doi:10.4028/ www.scientific.net/AMR.267.372

[16] Al-e-hashem, S. M. J. M.; Malekly, H.; Aryanezhad, M. B. (2011). A multi-objective robust optimization model for multi-product multi-site aggregate production planning in a supply chain under uncertainty, International Journal of Production Economics, Vol. 134, No. 1, 28-42, doi:10.1016/j.ijpe.2011.01.027

[17] Rockwell Automation. Arena, from http://www.arenasimulation.com/Arena_Home.aspx, accessed on 10-May-2012

[18] Altiok, T.; Melamed, B. (2007). Simulation Modeling and Analysis with ARENA, Academic Press, Burlington

[19] Krajewski, L.; Ritzman, L.; Malhotra, M. K. (2012). Operations Management: Processes and Supply Chains, Pearson Education, India 